\title{
Yoonho Lee, M.D., Ph.D., 1949 to 2019
}

\author{
Rong-Min Baek \\ Department of Plastic Surgery, Seoul National University College of Medicine, Seoul, Korea
}

Professor Yoonho Lee was an outstanding surgeon, respected professor, beloved father, and profoundly excellent teacher. On January 13, 2019, we lost this great man. The field of plastic surgery will never be the same without him.

Professor Lee was one of the pioneers of plastic surgery in Korea. He was born in Seoul in 1949. After graduating from Seoul National University College of Medicine in 1974, he became the first resident in the Department of Plastic Surgery at Seoul National University Hospital. He started his professorship in 1984, and served as the department chair from 1998 to 2004. He was a key player in making Korean plastic surgery internationally renowned, through his service as the 19th Chairman of the Korean Society of Plastic and Reconstructive Surgeons, the seventh President of the Korean Cleft PalateCraniofacial Association, the second President of the Korean Burn Society, and the International Confederation for Plastic Reconstructive and Aesthetic Surgery (IPRAS) Representative for Asia and the Far East. After his retirement in 2014, he became a board member of the Korea Medical Dispute Mediation and Arbitration Agency. His devotion as a caregiver for his patients was only matched by his solicitude for other plastic surgeons.

Professor Lee probably had the most intellectual enthusiasm and zest of anyone in the field of plastic surgery. He never stopped reading and contributing to new journal articles even after his retirement. However, his pure and loving heart was not only focused on knowledge—additionally, he truly loved his pupils. He spent almost all his spare time advising his pupils on their careers, as well as on life in general. He taught us how to become doctors, surgeons, and—first and foremost—decent people. He never sought wealth or luxury. We all remember the plain lunchbox he brought to work every day.

Korean plastic surgery became successful over the course of Professor Yoonho Lee's career, and he contributed tremendously to that success. He was our family. Nobody was ready to say good-bye to him, and it will take a very long time to accept his absence. However, the lessons he gave to us, the love he shared with his family and friends, the healing he provided to his patients, and finally, the passion he showed to the world will never be forgotten. May Professor Yoonho Lee, a deeply honorable man, rest in peace.

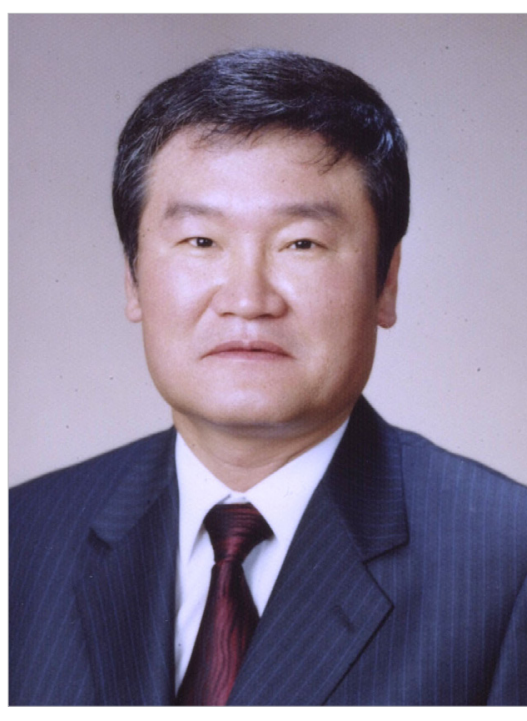

Yoonho Lee, M.D., Ph.D. 


\section{Notes}

\section{Conflict of interest}

No potential conflict of interest relevant to this article was reported.

\section{ORCID}

Rong-Min Baek https://orcid.org/0000-0002-0705-658X
Correspondence: Rong-Min Baek

Department of Plastic Surgery, Seoul National University College of Medicine,

82 Gumi-ro 173beon-gil, Bundang-gu, Seongnam 13620, Korea

Tel: +82-31-787-2203, Fax: +82-31-787-2203,E-mail: ronbaek@snu.ac.kr

Received: 11 Mar 2019• Revised: 13 Mar $2019 \bullet$ Accepted: 13 Mar 2019

pISSN: 2234-6163・ elSSN: 2234-6171

https://doi.org/10.5999/aps.2019.00276• Arch Plast Surg 2019;46:185-186 